\title{
Characterisation and Study of Compounds by Single Crystal X-ray Diffraction
}

\author{
Josefina Perles \\ Single Crystal X-ray Diffraction Laboratory, SIdI, Universidad Autónoma de Madrid, 28049 Madrid, Spain; \\ josefina.perles@uam.es; Tel.: +34-91479-3232
}

Received: 9 October 2020; Accepted: 11 October 2020; Published: 14 October 2020

A few years after the discovery in 1895 of X-rays by Röntgen, the first successful experiment single crystal X-ray diffraction (SCXRD) was reported by Laue, Friedrich, and Knipping [1]. Only a year later, in 1913, W. L. Bragg achieved the first structure solutions of $\mathrm{NaCl}$ and other alkaline metal halides, aided by his father, W. H. Bragg [2]. SCXRD has led to astonishing discoveries in the past century and, nowadays, it is behind many of the advances in different fields of science. Although initially mostly applied to natural mineral samples, it was soon discovered that the crystallisation of biological molecules and new chemical synthetic compounds could extend its application to other disciplines such as chemistry, biology, materials science, or pharmacology. As a consequence, SCXRD is today widely regarded as the most powerful technique for the structural study of crystalline samples at the atomic level, regardless of the chemical nature of the sample.

The structure solution of a crystalline substance can determine with high precision the location of the atoms in the crystal, as well as the strength of interatomic bonds and supramolecular interactions, and consequently plays a crucial role in the interpretation of the physicochemical properties of many substances. SCXRD is not only a unique characterisation tool, but the most effective resource to study the relationship between structure and properties in materials. The articles collected in this Special Issue illustrate the diverse fields where it can be applied, as well as the valuable information that can be obtained from the structure solution of single crystals.

Two of the articles focus on the structural study of medicinal compounds. In the paper by Nugrahani and collaborators [3], the authors report the crystallisation and structural determination of a new pseudopolymorph of the antibiotic drug ciprofloxacin salicylate. The meticulous structural study explains why the solubility of this polymorph improves the one measured for the previously reported crystal and describes an easy method to remove the water molecules present in the crystalline form. Rusew and coworkers [4] studied quaternary ammonium derivatives of 4-pyrrolidino pyridine with antibacterial activity. The different packings of the molecules in the crystals, due to the supramolecular forces, are comprehensively described and related to the respective thermal stability of the solids. The antibacterial activities of the new compounds were tested against E. coli and S. aureus, and compared to the reference kanamycin, finding that two of them exhibit improved effects.

Six of the contributions in this Special Issue are focused on the detailed analysis of the supramolecular interactions. Ferjani [5] presents a thorough structural study of a new molecular iodobismuthate, including a Hirshfeld surface analysis, to describe the supramolecular interactions in the crystal. Some theoretical methods are also tested to simulate the crystal morphology, and the simulations are compared with the experimental results. In the work presented by Portalone [6], the influence of the position and nature of the halogen atom in several derivatives of uracil is meticulously analysed, with the aim to study the formation of halogen bonds and the preferred donor and acceptor sites in $\mathrm{C}-\mathrm{O} \cdots \mathrm{X}$ interactions. The role played by halogen bonds is also analysed, together with the effect of the existing hydrogen bonds in the supramolecular arrangements. Klein and coworkers [7] also focus on the substituent effects in the molecular packing, in this case, regarding 
a series of new $4^{\prime}$-substituted terpyridines. The crystal structure determination of the different compounds allows the complete study of supramolecular interactions between the aromatic rings in the solid state, as well as other non-covalent bonds in the crystals. Prior and collaborators [8] performed the synthesis and study of three salts of anionic coordination polymers. A detailed description of the compounds, composed of dirhodium paddlewheel and tetracyanido-metallate building blocks, is presented together with a comparative study of the packing of the anionic chains and the interstitial $\mathrm{PPh}_{4}{ }^{+}$cations. The contribution of Fresta and colleagues [9] involves the thorough structural study of another coordination compound, namely a molecular cationic iridium derivative that crystallizes with hexafluorophosphate. This structure shows the uncommon feature of three ionic pairs in the asymmetric unit, and the presented Hirshfeld surface analysis helps to understand the small differences between the three cation-anion couples. Mphahlele et al. [10] describe the obtention and study of several 2-aminochalcone epoxides, with a special interest on the conformational features of these molecules. They present also a complete description of the supramolecular interactions in the crystal, together with a Hirshfeld analysis. The study in the solid state is complemented with the observation of the molecules in solution aided by NMR spectroscopy.

Finally, three of the papers correlate the structural information with the properties exhibited by the materials studied. Dory et al. [11] report the first complete structural characterization of a furan-based polyacetylene and clarify the topochemical polymerization of the molecular precursor after a careful study of the supramolecular interactions in the solid state. Keller and colleagues [12] describe the synthesis and characterisation of several copper compounds with $\mathrm{P}, \mathrm{P}$ - and $\mathrm{N}, \mathrm{N}$ - donor ligands and study the influence of the extended $\pi$-system and the supramolecular arrangement in the resulting photoluminescence of the solids. They also performed an interesting bibliographic review to compare the packing features and quantum yields of the new compounds with the related ones previously reported in the literature. Martinez-Martin and collaborators [13] describe the synthesis and study of two ligands and several coordination polymers with rare-earth metals ytterbium and terbium, as well as the structure solution of all of them. The detailed study of the new materials allows them to explain the structural differences and their influence on the luminescence exhibited by the coordination compounds.

In summary, this Special Issue Characterisation and Study of Compounds by Single Crystal X-ray Diffraction collects eleven stimulating articles by researchers from different fields of science, who have profited from the detailed structural information yielded by SCXRD. It has been used, in combination with complementary techniques, as a unique tool both to perform an in-depth analysis of new compounds presented, and also to understand the properties that they exhibit.

Funding: This research received no external funding.

Acknowledgments: The Guest Editor for this Special Issue wants to thank all of the authors of the papers collected here for submitting their remarkable work, as well as the publishing staff from Crystals, especially Jenny Cheng, for their assistance and support.

Conflicts of Interest: The author declares no conflict of interest.

\section{References}

1. Friedrich, W.; Knipping, P.; Laue, M. Interferenz-Erscheinungen bei Röntgenstrahlen. Sitzungsber. K. Bayer. Akad. Wiss. Math. Phys. Kl. 1912, 303-322.

2. Bragg, W.L. The Structure of Some Crystals as Indicated by their Diffractions of X-rays. Proc. R. Soc. Lond. A 1913, 89, 248-277. [CrossRef]

3. Nugrahani, I.; Tjengal, B.; Gusdinar, T.; Horikawa, A.; Uekusa, H. A Comprehensive Study of a New 1.75 Hydrate of Ciprofloxacin Salicylate: SCXRD Structure Determination, Solid Characterization, Water Stability, Solubility, and Dissolution Study. Crystals 2020, 10, 349. [CrossRef]

4. Rusew, R.; Kurteva, V.; Shivachev, B. Novel Quaternary Ammonium Derivatives of 4-Pyrrolidino Pyridine: Synthesis, Structural, Thermal, and Antibacterial Studies. Crystals 2020, 10, 339. [CrossRef] 
5. Ferjani, H. Structural, Hirshfeld Surface Analysis, Morphological Approach, and Spectroscopic Study of New Hybrid Iodobismuthate Containing Tetranuclear 0D Cluster $\mathrm{Bi}_{4} \mathrm{I}_{16} \cdot 4\left(\mathrm{C}_{6} \mathrm{H}_{9} \mathrm{~N}_{2}\right) 2\left(\mathrm{H}_{2} \mathrm{O}\right)$. Crystals 2020, 10, 397. [CrossRef]

6. Portalone, G. Site Selectivity of Halogen Oxygen Bonding in 5- and 6-Haloderivatives of Uracil. Crystals 2019, 9, 467. [CrossRef]

7. Klein, Y.M.; Prescimone, A.; Becker, M.; Constable, E.C.; Housecroft, C.E. Substituent Effects in the Crystal Packing of Derivatives of 4'-Phenyl-2,2':6',2"-Terpyridine. Crystals 2019, 9, 110. [CrossRef]

8. Prior, D.; Cortijo, M.; González-Prieto, R.; Herrero, S.; Jiménez-Aparicio, R.; Perles, J.; Priego, J.L. Linear One-Dimensional Coordination Polymers Constructed by Dirhodium Paddlewheel and Tetracyanido-Metallate Building Blocks. Crystals 2019, 9, 614. [CrossRef]

9. Fresta, E.; Milanesio, M.; Volpi, G.; Barolo, C.; Conterosito, E. Synthesis and Crystal Structure of Bis(2-phenylpyridine-C,N')-bis(acetonitrile)iridium(III)hexafluorophosphate Showing Three Anion/Cation Couples in the Asymmetric Unit. Crystals 2019, 9, 617. [CrossRef]

10. Mphahlele, M.J.; Maluleka, M.M.; Mampa, R.M. Elucidation of the Structure of the 2-amino-3,5-Dibromochalcone Epoxides in Solution and Solid State. Crystals 2019, 9, 277. [CrossRef]

11. Dory, Y.; Caron, M.; Duguay, V.O.; Chicoine-Ouellet, L.; Fortin, D.; Baillargeon, P. Preparation and Single Crystal Structure Determination of the First Biobased Furan-Polydiacetylene Using Topochemical Polymerization. Crystals 2019, 9, 448. [CrossRef]

12. Keller, S.; Alkan-Zambada, M.; Prescimone, A.; Constable, E.C.; Housecroft, C.E. Extended $\pi$-Systems in Diimine Ligands in $\left[\mathrm{Cu}\left(\mathrm{P}^{\wedge} \mathrm{P}\right)\left(\mathrm{N}^{\wedge} \mathrm{N}\right)\right]\left[\mathrm{PF}_{6}\right]$ Complexes: From 2,2'-Bipyridine to 2-(Pyridin-2-yl)Quinoline. Crystals 2020, 10, 255. [CrossRef]

13. Martinez-Martin, P.; Perles, J.; Rodríguez-Ubis, J.C. Crystal Structure Dependence of the Energy Transfer from $\mathrm{Tb}(\mathrm{III})$ to $\mathrm{Yb}(\mathrm{III})$ in Metal-Organic Frameworks Based in Bispyrazolylpyridines. Crystals 2020, 10, 69. [CrossRef]

Publisher's Note: MDPI stays neutral with regard to jurisdictional claims in published maps and institutional affiliations.

(C) 2020 by the author. Licensee MDPI, Basel, Switzerland. This article is an open access article distributed under the terms and conditions of the Creative Commons Attribution (CC BY) license (http://creativecommons.org/licenses/by/4.0/). 